\title{
ETHICS AND LAW
}

\section{The role of the courts in clinical decision making}

K Leask

Arch Dis Child 2005;90:1256-1258. doi: 10.1136/adc.2005.083097

With advances in medical technology more can be offered with respect to treatment, for example, in neonates born prematurely. This raises the public's expectations of what medical professionals can offer and puts healthcare professionals under pressure to continue treatment, which may ultimately be futile. The courts may be asked to intervene in those cases where there is disagreement between parents and healthcare professionals. This may occur where doctors refuse to instigate or continue futile treatments or where treatment is not felt to be in the best interests of the patient. Cases may also be referred to the courts where doctors feel treatment options do exist but those with parental responsibility refuse to consent. Disagreement may also occur between parents. The best interests of the child are paramount and their welfare should always be the primary consideration. However, the court's opinion will be increasingly sought as parents' expectations increase and doctors fear litigation if they act against the parents' wishes. This paper reviews the role of the courts, using a number of high profile cases as examples. While the courts generally support the views of the healthcare professional, this cannot be guaranteed.

Correspondence to:

Dr K Leask, Academic Unit of Medical Genetics and Regional Genetics Service, St Mary's Hospital, Hathersage Road, Manchester M13 $\mathrm{OJH}$, UK; kmleask@doctors.org.uk

Accepted 19 August 2005 Published Online First 20 September 2005
A child is said to be "Gillick competent"1 when they are deemed to have sufficient understanding and intelligence to enable them to understand fully their proposed management. Before this level of competence is reached, decisions regarding their physical and emotional wellbeing have to be made on their behalf, including decisions regarding their medical treatment. Parents are said to be best placed to make these decisions as they above all others should have their child's welfare at heart. However, as the case law reveals, there are occasions when decisions made by parents are not thought to be in the best interests of their child, and at this point the courts may be asked to intervene.

There are generally three types of case which appear before the courts. The first of these includes those cases in which doctors feel further active medical intervention will not change the outcome and death is inevitable, but parents disagree. A further dilemma includes those cases where, although death is not inevitable, treatment is futile as the child's life is so severely impaired. Courts in these cases may authorise the withdrawal of care or agree that aggressive resuscitation would not be appropriate. The final category is where the proposed treatment may provide a cure for the child but despite this the parents refuse to give their consent. This is often, but by no means exclusively, related to cultural and religious beliefs.

THE ROLE OF PARENTS AND THE COURT Young children depend on their parents to make good decisions on their behalf. The obligations of parents are set out in the Children Act $1989^{2}$ which refers to "parental responsibility". This is a legal concept which not all biological parents may possess. Although parents have the right to raise their children according to their own values, common law dictates that these rights are present to be of benefit to the child and should be concerned primarily with the child's best interests. The values of parents can impact on the medical care of a child; for example, the Jehovah's Witness parent who refuses a life saving blood transfusion for their child. It is where parents' interests have serious consequences for their child, that the courts may be asked to intervene. The court's primary consideration is for the welfare of the child. It may become involved in a number of ways. The jurisdiction of the High Court may make a child a ward of court and assume responsibility for their welfare. The Official Solicitor may be appointed to act as the child's guardian. Since the Children Act came into force, the use of wardship may be limited as the court may prefer to make a section 8 order instead. Two of these orders, relevant to medical treatment, are the Prohibited Steps order and the Specific Issue order. The former may apply where one parent wants their child to undergo a medical procedure but the other parent does not. The parent who refuses may take out such an order to ensure the procedure does not go ahead by preventing the other parent from being able to independently consent. A Specific Issue order is designed to deal with one off decisions which need to be taken on behalf of the child. This often relates to medical treatment or education. Again when considering whether or not to take out such an order, the court treats the child's welfare as paramount.

\section{THE DOCTOR'S DILEMMA}

Parents have to make life and death decisions regarding and on behalf of their children. It is the healthcare professional's job to advise and guide parents through this difficult time based on their clinical expertise. Consideration has to be made with regard to saving lives but also to the prevention of suffering. Although those with parental responsibility have the power to give, and withhold consent, it is only valid if they are acting in their child's best interests. Often 
when a parent refuses appropriate and necessary treatment for their child, healthcare professionals may be uncertain of their position legally and therefore seek authorisation from the court prior to proceeding. ${ }^{3}$ It appears, on review of the case law,,$^{4-8}$ that the courts, by and large, authorise the plans of healthcare professionals, providing there is no disagreement between experts. This support is not automatic and is not the legal rule, but is, in practice, a common outcome. Some advocate doctors as decision makers, believing this should apply to those decisions that are incontrovertibly in the child's best interests. Consultation with other professionals and the parents would only take place where there is a difference in opinion as to what is the best practice. Some argue that this would allow all children to have access to the most beneficial treatment, regardless of the values of the parents. ${ }^{9}$ How difficult this would be in practice is difficult to say. Strict guidelines would have to be laid down as to what constitutes appropriate treatment. Doctors may still feel some trepidation in making such decisions about someone else's children, particularly in these litigious times.

\section{THE COURT'S APPROACH}

When a doctor is faced with a critically ill child whose life depends on certain medical interventions, but who is not accompanied by his or her parents, the doctor can treat the child, providing this is with primary concern to the child's welfare, without the consent of the parents. The doctor is acting out of necessity in order to treat the child appropriately. If the doctor is acting in such a way as would be agreed by other health professionals he is not acting illegally. A doctor would also be concerned to avoid any civil liability by meeting his duty of care. This principle is supported by case law. ${ }^{10}$ A doctor is under a common law duty to act in the best interests of the child and therefore should not be subject to actions of negligence or trespass in emergency situations. ${ }^{10}$ If life saving treatment is required and parents are available but refuse to consent, and time does not allow the seeking of judicial advice, the doctor may go ahead with immediate treatment. ${ }^{11}$ If time does permit, judicial advice can be sought, and clearly these decisions have to be made with the utmost speed.

As already mentioned the court's decisions are made based on the "best interests" of the child, and saving a life will usually prevail over the parents' religious or cultural views. ${ }^{12}$ Having said this the courts are careful to take into account these views when assessing a case as well as taking into account the success of the proposed treatment, any pain and suffering that the child is likely to experience and also, importantly, the child's future quality of life.

Contained within the Children Act 1989 are certain issues on which the judge will place importance. These issues include the child's physical and emotional wellbeing and the likely effect of any circumstantial changes; the child's background will also be taken into account and any harm that they might suffer. In a more recent case $^{13}$ the judge referred to the child's life as "intolerable". While "intolerability" in itself is not a legal test, the "best interests" test is.

As well as the Children Act, legal decisions within the UK regarding withholding and withdrawing care from critically ill children, are also supported by the Human Rights Act (1998). This act emphasises the universal right to life. In view of this, NHS authorities and those working within health care must acknowledge the fundamental rights of children and their families. There are however clearly situations where there is conflict, resulting in the dilemmas discussed.

\section{EXAMPLES FROM CASE LAW \\ Refusal of parental consent}

In the case of Re ${ }^{14},{ }^{14}$ a child was born with biliary atresia and a liver transplant was the only available treatment. The parents refused to consent to transplantation as they felt it was not in the child's best interests. The advice of another paediatrician was sought who also urged the parents to consent. When a liver became available an approach was made to the court to intervene under the Children Act. While the initial ruling held that the parents' view was unreasonable, the Court of Appeal overturned this decision. The determining reason the judges cited in their decision was a consequential one. An expert witness stated that the effects on the mother of being forced to continue to care for her child having undergone treatment to which she had not consented would not be in the best interests of the child. Therefore, despite medical opinion being unanimous in its recommendations for surgery, which involved relatively minor risk when compared to the long term benefit of the child, the court supported the views of the parents.

In $\operatorname{Re~} S,{ }^{15}$ the parents of the child in question were Jehovah's Witnesses. They refused to allow their child to have a blood transfusion. Doctors sought the court's advice who sanctioned the use of blood products. There are other cases of a similar nature to Re S with similar outcomes. It is likely that any future cases will allow doctors to perform blood transfusions on these children despite their parents' religious views. This will prevent the need for healthcare professionals to approach the courts each time a similar situation arises.

Re $\mathrm{B}^{16}$ involves refusal of consent by parents for a surgical procedure on their baby. The baby in question was born with Down's syndrome with an associated intestinal obstruction. The parents felt it was in the best interests of the child not to have a surgical correction, but be allowed to die. The doctors disagreed, believing the child should undergo surgery and appealed to the court for advice. B was made a ward of court. The decision made by the court was based on the likely quality of life B should expect following the procedure. Despite the fact that the child had Down's syndrome a reasonable quality of life was expected.

\section{The importance of "quality of life"}

This "quality of life" approach was also applied in the case of Re $\mathrm{J},{ }^{17}$ which involved a severely brain damaged premature baby who was expected to have severe mental and physical disabilities in the future. The court approved doctor's decision not to reventilate this baby should the need arise, as the future outlook was so bleak. The child's quality of life was a major consideration during the decision making process. Parents have high expectations, but these may not be realistic, and therefore doctors find themselves in a position where they need to seek advice from the courts to prevent death being prolonged.

Sanctity and quality of life issues were also raised in the recent case of Charlotte Wyatt. ${ }^{13}$ Briefly, Charlotte was born at 26 weeks' gestation and had multiple medical problems. Doctors were concerned that reventilation, should Charlotte stop breathing, would cause her pain and distress. In short it would not be in her best interests. The parents disagreed. The decision by the judge made allowances for the doctrine of the sanctity of life, but believed that Charlotte's life would be "intolerable" should such intervention take place.

\section{Where death is inevitable}

Re $\mathrm{C}^{8}$ involves a young child with spinal muscular atrophy. C was on a ventilator and doctors felt that should ventilation be continued, $\mathrm{C}$ would suffer and become distressed; they felt it was in $C^{\prime}$ s best interests for ventilation to be withdrawn. 
However, the parents disagreed; they wanted ventilation to continue. The child was made a ward of court. Again, addressing the child's best interests, the court considered the facts of the case and conceded that it would not be appropriate for $\mathrm{C}$ to remain ventilated.

\section{Where treatment is futile}

Re $\mathrm{C}^{18}$ concerns a baby, born prematurely, who developed neonatal meningitis resulting in severe disabilities, including loss of vision and hearing. The child was made a ward of court to allow consideration as to whether artificial feeding and ventilation should be discontinued and to relieve the parents of their "grave responsibility". ${ }^{18}$ The parents themselves had asked the medical professionals caring for their child to consider withdrawal of treatment and instructed an independent consultant to give his opinion. All those involved, including the parents, agreed that this was in the best interests of the child. This was supported by the court. During the case it was questioned as to why the court had needed to intervene on this occasion. The judge was called on to make observations as to when it would be appropriate for doctors in this position to seek the leave of the court. The judge felt it was inappropriate to make general observations as each case must be considered on its merits. This may increase the anxieties of doctors as to when to seek advice from the court. In this case the child had been made a ward of court to ease the burden of the decision from the doctors, and particularly, and more understandably, from the parents.

\section{CONCLUSION}

There is full support from the law with respect to family autonomy and for those with parental responsibility to bestow their chosen values of their children. The European Convention of Human Rights promotes these ideals, with Article 8 enforcing the right to respect for family and private life, and denouncing interference by public authorities. This concept is reiterated in the Children Act 1989. However, it is necessary that legal limits restrict the rights of parents where a risk of potential harm exists to the children in their care. While parents must always be considered as best placed to make decisions on behalf of their children, there must always be a safeguard to protect those children whose parents may not act in their child's best interests, regardless of how unintentional this may be, and allow those children, where appropriate, to reach an age where they can decide for themselves which is the most appropriate course of action for them.

These cases illustrate situations in which the court's opinion should be sought. The case of Re T shows that the court's response cannot be predicted. This, from the point of view of healthcare professionals, shows the importance of consulting the court before acting against a parent's wish if they are to avoid litigation and to ensure that the welfare of the child is upheld.

Until the Wyatt case in 2004, these types of cases were heard privately. The media and public interest in the Wyatt case may result in more parents and those with parental responsibility challenging decisions made by healthcare professionals.

\section{ACKNOWLEDGEMENTS}

We acknowledge Catherine Stanton, Centre for Social Ethics and Policy, School of Law, University of Manchester, Oxford Road, Manchester.

Competing interests: none

\section{REFERENCES}

1 Gillick v West Norfolk and Wisbech Area Health Authority [1986] AC 112 2 Children Act 1989.

3 Montgomery J. Health care law, 2nd edn. Oxford: Oxford University Press, 2003:304.

$4 \operatorname{Re} S$ (a minor) (wardship: medical treatment) [1993] 1 FLR 376.

$5 \operatorname{Re} C$ (a child) (HIV testing) [2000] Fam 48.

$6 \operatorname{Re} B$ (a minor) (wardship: medical treatment) [1981] 1 WLR 1421.

7 Re J (a minor) (wardship: medical treatment) [1990] 3 All ER 930 CA.

$8 \operatorname{Re} C$ (a minor) (wardship: medical treatment) [1997] 40 BMLR 31.

9 Lavery R. Routine medical treatment of children. Journal of Social Welfare Law 1990;375:381.

10 F v West Berkshire Health Authority [1989] 4 BMLR 1.

11 Brazier M. Medicine, patients and the law, 3rd edn. London: Penguin Books, 2003:353.

12 Re S (a minor) (wardship: medical treatment) [1993] 1 FLR 376.

13 Re Wyatt (a child) (medical treatment: parents' consent) [2004] EWHC 2247.

$14 \operatorname{Re} T$ (a minor) (wardship: medical treatment) [1997] 1 WLR 242 CA.

15 Re S (a minor) (wardship: medical treatment) [1993] 1 FLR 376

$16 \operatorname{Re} B$ (a minor) (wardship: medical treatment) [1981] 1 WLR 1421.

$17 \operatorname{Re} J$ (a minor) (wardship: medical treatment) [1990] 3 All ER 930 CA.

$18 \operatorname{Re} C$ (a baby) [1996] 2 FLR 43. 